\title{
Phase 2a safety and immunogenicity testing of DNA and recombinant modified vaccinia ankara virus vaccines expressing virus-like particles
}

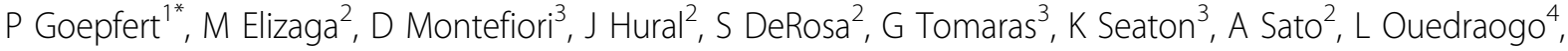 \\ Y Donastorg ${ }^{5}$, M Cardinali $^{4}$, J Lama $^{6}$, L Baden $^{7}$, M Keefer $^{8}$, J McElrath $^{9}$, S Kalams $^{10}$, H Robinson $^{11}$
}

From AIDS Vaccine 2012

Boston, MA, USA. 9-12 September 2012

\section{Background}

The Phase 2a HVTN 205 trial was undertaken to further compare full-dose regimens of DNA priming with MVA boosting and MVA priming and boosting.

\section{Methods}

150 vaccinia-naïve participants were inoculated i.m. via needle and syringe with $3 \mathrm{mg}$ of pGA2/JS7 DNA at months 0 and 2, and 1x108 TCID50 of MVA/HIV62B at months 4 and 6 (DDMM regimen). 75 participants received 1x108 TCID50 of MVA/HIV62B at months 0 , 2, and 6 (MMM regimen) and 75 received placebo. While the safety data are still blinded, the vaccine regimens appeared safe and well tolerated. Immune studies were performed at 2 weeks following the final vaccination.

\section{Results}

Similar to Phase 1 testing, the DDMM regimen induced higher rates of $\mathrm{T}$ cell responses whereas the MMM regimen induced higher rates of antibody responses. CD4 $\mathrm{T}$ cell responses were elicited in 65\% of the DDMM and $43 \%$ of the MMM recipients $(\mathrm{p}=0.01)$ whereas CD8 T cells were induced in $22 \%$ and $16 \%$, respectively. The majority of $\mathrm{T}$ cells were directed against Gag with fewer against Env and only occasional responses to Pol. gp120 IgG antibodies were demonstrated in $45 \%$ and $68 \%$ of the DDMM and MMM recipients, respectively $(\mathrm{p}=0.001)$. gp41 IgG antibodies were seen in over $90 \%$ of both groups. The magnitudes of serum IgG responses exceeded the magnitudes of serum IgA responses by $>10$ fold with higher IgG to IgA responses being present in the MMM group $(\mathrm{p}=0.03)$. The antibody avidity index to the gp41 immunodominant epitope, a preclinical correlate of protection against infection demonstrated levels of affinity maturation comparable to preclinical studies. Sporadic weak neutralizing activity against Tier 1 and Tier 2 viruses was seen in both groups and was greater for MVA alone.

\section{Conclusion}

The vaccine safety data and immune responses seen here are supportive of further testing.

\section{Author details \\ ${ }^{1}$ University of Alabama at Birmignham, Birmingham, AL, USA. ${ }^{2}$ Fred Hutchinson Cancer Research Institute, Seattle, WA, USA. ${ }^{3}$ Duke University, Durham, NC, USA. ${ }^{4}$ NIAID Vaccine Clinical Research Branch, Bethesda, MD, USA. ${ }^{5}$ Unidad de Vacunas IDCP-COIN-DIGECITSS, Santo Dominago, Dominican Republic. ${ }^{6}$ Asociacion Civil IMPACTA Salud y Educacion, Barranco, Lima, Peru. ${ }^{7}$ Brigham and Women's Hospital, Boston, MA, USA. ${ }^{8}$ University of Rochester, Rochester, NY, USA. ${ }^{9}$ Fred Hutchinson Cancer Research Instituted, Seattle, WA, USA. ${ }^{10}$ Vanderbilt University, Nashville, TN, USA. ${ }^{11}$ GeoVax Inc., Smyrna, GA, USA.}

Published: 13 September 2012

doi:10.1186/1742-4690-9-S2-056

Cite this article as: Goepfert et al:: Phase 2a safety and immunogenicity testing of DNA and recombinant modified vaccinia ankara virus vaccines expressing virus-like particles. Retrovirology 2012 9(Suppl 2):O56.

'University of Alabama at Birmignham, Birmingham, AL, USA

Full list of author information is available at the end of the article

(c) 2012 Goepfert et al; licensee BioMed Central Ltd. This is an Open Access article distributed under the terms of the Creative 